\section{Iron Chlorotic Melon Germplasm C940-fe}

\author{
Perry E. Nugent ${ }^{1}$ \\ U.S. Vegetable Laboratory, Agricultural Research Service, U.S. Department \\ of Agriculture, 2875 Savannah Highway, Charleston, SC 29414
}

Additional index words. muskmelon, cantaloupe, iron deficiency, nutrient deficiency, Cucumis melo

The Fe chlorotic melon C940-fe germplasm (Cucumis melo L.) mutant was approved for release in 1991 by the Agricultural Research Service, U.S. Dept. of Agriculture. This mutant is controlled by a single recessive gene with the symbol $f e$ (Pitrat, 1990), and it is independent of the virescent $(v)$ gene (Nugent and Bhella, 1988). The mutant is being used for genetic, Fe metabolism, and nutrient uptake studies and also has potential for use in linkage and other genetic research (Hoffman and Nugent, 1973; Jolley et al., 1991; Nugent, 1987).

\section{Origin}

C940-fe (Nugent and Bhella, 1988) originated in 1984 as a mutant in a population of 'Edisto' melon seedlings (Fig. 1). This mutant expresses Fe-deficiency-related retarded growth and interveinal chlorosis of young leaves. The chlorosis was partially corrected by adding supplemental Fe to allow production of male flowers before the original plant died. Pollen from these male flowers was used to pollinate 'Mainstream' and a line carrying the virescent mutant $(v)$ (Hoffman and Nugent, 1973). The $F_{1}$ plants derived from crosses were normal, but the fe gene segregated in the $\mathrm{F}_{2}$ generations of both crosses. The germplasm released as C940-fe is the result of self-pollinating $\mathrm{F}_{4} \mathrm{Fe}$-deficient mutants from original 'Edisto' $\times$ 'Mainstream' matings.

\section{Description}

C940-fe seedlings have normal green cotyledons, but the first true leaves are yellow with green veins (Fig. 2). The Fe content of the chlorotic leaves is very low, between 23 and $35 \mathrm{mg} \cdot \mathrm{g}^{-1}$ (Jolley, 1991). C940-fe plants are stunted and become white and die unless supplemental $\mathrm{Fe}$ is provided, which ensures normal development. C940-fe segregates for vein tracts (sutures) and for the number of fruit per plant that weigh 3 to $2.2 \mathrm{~kg}$ (Fig. 3). Although normal selections from crosses with C940-fe have produced vigorous plants and

Received for publication 25 Feb. 1993. Accepted for publication 6 Aug. 1993. The cost of publishing this paper was defrayed in part by the payment of page charges. Under postal regulations, this paper therefore must be hereby marked advertisement solely to indicate this fact.

'Research Horticulturist. attractive fruit (Fig. 2), yields were sometimes low. Fruit quality is good (10\% to $12 \%$ soluble solids concentration), particularly for those plants whose fruit look like 'Edisto' and have the high yield of 'Mainstream', i.e., four fruit per plant.

\section{Uses}

Iron-deficient plants lack the normal $\mathrm{Fe}$ uptake mechanisms found in the two parent cultivars Mainstream and Edisto (Jolley et al., 1991). The mutant has also been found to be unusual in its limited ability to absorb Mn. Preliminary research (Jolley et al., 1991)
Fig. 1. Pedigree of C940-fe melon. showed that C940-fe maybe valuable for Mnrelated growth studies (e.g., Fe uptake, transport, and use). The germplasm should find utility as a genetic marker in gene-mapping studies. If the intent is to use this germplasm without the Fe inefficiency for cultivar improvement, this gene can be eliminated by self-pollinating the normal plants in a segregating population and identifying nonsegregating families in progeny tests. In hybrid production $(\mathrm{FeFe} \times f e f e)$, the recessive $f e$ gene is not expressed and therefore has no effect on the F, plant $(\mathrm{FeFe})$.

\section{Culture}

In preliminary studies, C940-fe plants develop chlorophyll and grow slowly in 3 peatmoss: 1 sand, supplemented with a complete mix (NUTRILEAF 60; Miller Chemical and Fertilizer Corp., Hanover, Pa.) and 4 ppm chelated $\mathrm{Fe}$ in tap water. In later tests, $2 \mathrm{~g}$ chelated Fe (Suquestrene 330 Fe; Ciba-Geigy Corp., Greensboro, N. C.) per liter of water can also maintain the health of most deficient seedlings. Applying $250 \mathrm{ml}$ of this solution to the soil around the plant's base will alleviate deficiency symptoms. (Nugent and Bhella,
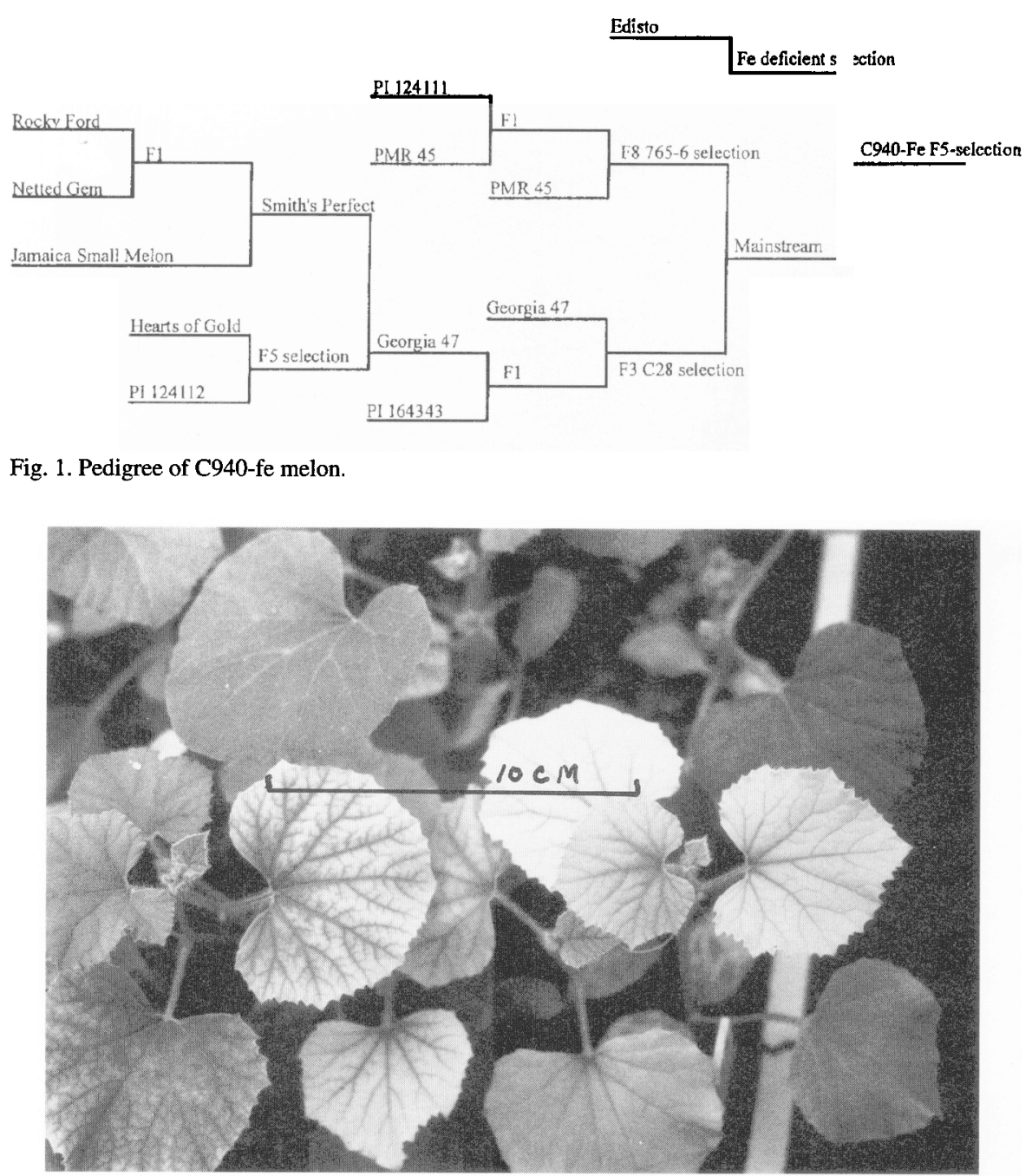

Fig. 2. Seedlings (4 weeks old) of C940-fe melon showing Fe deficiency. 


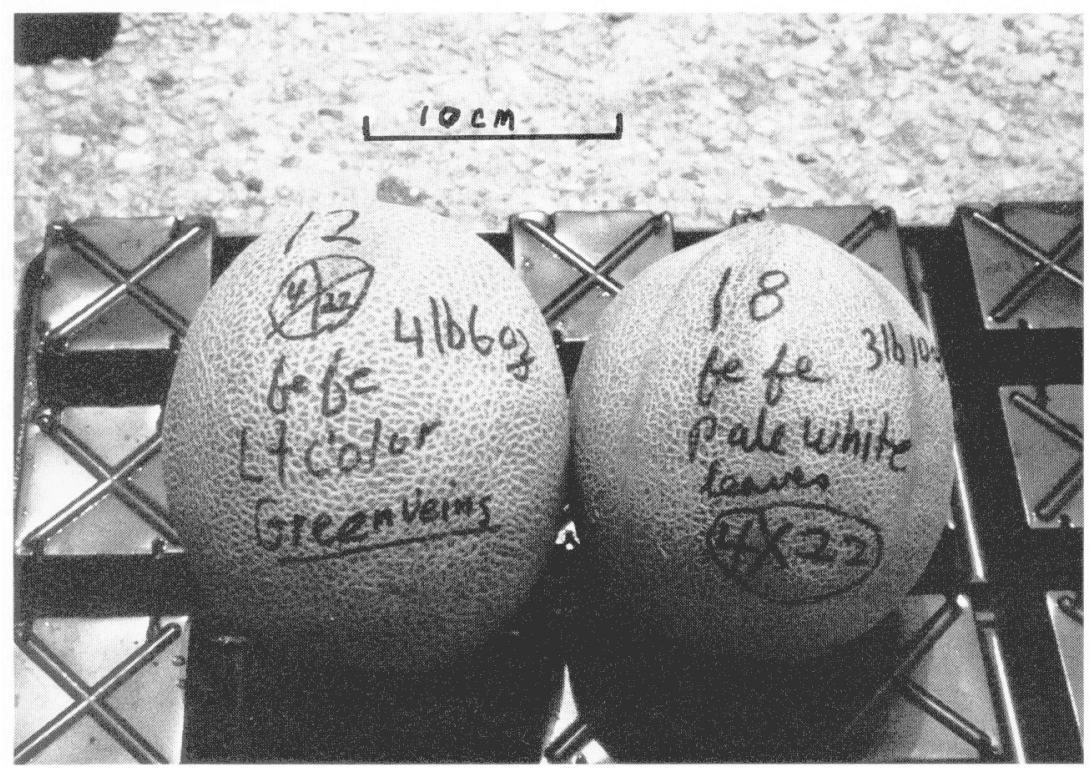

Fig. 3. Fruit of C940-fe melon. Means were fruit weight, $1.8 \mathrm{~kg}$; diameter, $15.0 \mathrm{~cm}$; and length, $16.5 \mathrm{~cm}$.

\section{Availability}

Samples of this accession are available from P.E.N. on a pro-rata basis to breeders and other scientists. Seed recipients are asked to give appropriate recognition of the germplasm source if it is used in research or in developing a new germplasm, parent line, or cultivar,

\section{Literature Cited}

Hoffman,J.C.andP.E. Nugent. 1973. Inheritance of a virescent mutant in muskmelon. J. Hered. 64:311-316.

Jolley, V.D., J.C. Brown, and P.E. Nugent. 1991. A geneticallycontrolledresponsetoFe-deficiency stress in muskmelon. Plant\& Soil 130: 87-92.

Nugent, P.E. 1987. C879-J1 and C879-J2 virescent mutantmuskmelonbreedinglines. HortScience 22(2):333-335.

Nugent, P.E. and H.S. Bhella.1987. An iron deficient mutant in muskmelon, Cucumis melo $\mathrm{L}$. HortScience22(5):722.(Abstr.)

Nugent, P.E. andH.S. Bhella. 1988. Anew chlorotic mutantofmuskmelon. HortScience 23(2):379_ 381.

Pitrat, M.-1990. Gene list for Cucumis melo L. Cucurbit Genet. Coop. 13:58-68. 